\title{
QUANDO A VIOLÊNCIA INFANTO-JUVENIL INDAGA A PEDAGOGIA
}

\author{
Miguel GonZÁlez Arroyo*
}

\begin{abstract}
RESUMO: Este texto se propõe a levantar algumas indagações que vêm de um dos traços mais inquietantes da contemporaneidade: a violência, e de maneira particular a violência infanto-juvenil. Esta incomoda e indaga a sociedade e a Pedagogia, as pesquisas, a reflexão teórica e o fazer educativos. Focalizo alguns pontos: a categoria violentos estaria se impondo como um novo parâmetro segregador na sociedade e nas escolas? Estariam em questão os avanços havidos na conformação do público e da escola como espaço público? As reações à violência estariam mostrando a fragilidade da proclamação da educação como direito de todos? E a fragilidade do reconhecimento da infância-adolescência como sujeitos de direitos? Destaco que as reaçôes à violência infanto-juvenil repóem a tradicional disputa pelo imaginário sobre o povo e sobre a infância-adolescência populares. De cada um desses traços chegam indagaçôes para a Pedagogia.
\end{abstract}

Palavras-chave: Educação. Infância. Adolescência. Violência. Direitos.

\section{WHEN CHILD AND YOUTH VIOLENCE QUESTIONS PEDAGOGY}

ABSTRACT: This text proposes to raise some questions emerging from one of the most worrying features of present days: violence and, more particularly, child and youth violence, which bothers and questions society and pedagogy, research, the theoretical reflection and the educational practice. The paper focuses on some points: Is the category "violent" imposing itself as a new segregating parameter in society and in schools? Are the progresses made in the conformation of the public and of school as a public space being questioned? Are the reactions to violence showing the weakness of proclaiming education as a right for all? And the weakness of recognizing children

Doutor em Educação e professor titular emérito da Faculdade de Educação da Universidade Federal de Minas Gerais (UFMG).E-mail: g.arroyo@uol.com.br 
and teenagers as subjects of rights? It also highlights that the reactions to child and youth violence places again the traditional dispute for the imaginary on the people and on popular children and teenagers. Each of these features sends us questions for pedagogy.

Key words: Education. Childhood. Teenage. Violence. Rights.

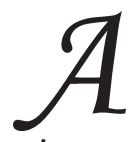

violência vem sendo objeto de pesquisas e de reflexão teórica. Especial atenção vem merecendo a violência infanto-juvenil, ora em suas diversas formas de violentar as crianças, adolescentes e jovens (exploração sexual, tráfico, trabalho infantil, desemprego, sobrevivência, fome, desproteção, maus-tratos, mortes), ora nas diversas formas de envolvimento da infância, adolescência e juventude nas redes de tráfico, agressão, roubos, assaltos, mortes. Na pesquisa e reflexão têm despertado atenção especial as diversas formas de violência praticadas nas escolas (Abramovay et al., 2002).

Nestas reflexões não pretendo trazer dados sobre o tamanho das violências, nem sobre suas complexas causas econômicas, sociais nem sobre números de violências nas escolas. Parto desses dados, das pesquisas e análises, e observo as reações de repúdio e até de espanto diante das violências, e diante, sobretudo, de infâncias e adolescências tidas como infratoras. Concentro minha atenção nas reações da sociedade, da mídia, da academia, do campo do direito e das políticas sociais.

Sugiro no texto a urgência de pesquisar e teorizar sobre que impactos provocam as violências e as reaçóes à violência infanto-juvenil na função da escola e da docência, na imagem dos educandos especificamente na imagem da infância e adolescência populares. Em que aspectos desestabilizam concepções de educação, de formação e desenvolvimento humano. Desestabilizam as funções docentes e os referentes teóricos, ético-político-pedagógicos construídos no movimento de renovação teórico-pedagógica. Destaco as indagações que a violência infanto-juvenil traz para o repensar da teoria e prática educativa: Que perspectivas abrem para a formulação de políticas públicas? Que crenças desconstroem?

\section{Violência-violentos, novo parâmetro segregador?}

Algumas constatações merecem uma atenção inicial. O termo "violência" passou a unificar condutas diversificadas. Assim como outros 
termos, "terrorismo", "terroristas", por exemplo, os termos violência, violentos tornaram-se um referente de classificação e segregação de condutas, de pessoas e de coletivos. O termo "violência infanto-juvenil" faz referência à classificação de condutas de um determinado coletivo de crianças, adolescentes ou jovens, termo que os classifica e segrega como coletivo.

Por exemplo, o conjunto de condutas indisciplinadas que sempre aconteceram nas escolas passou a ser interpretado e classificado como violências, elevando a diversidade de condutas desviantes a essa condição e segregando os alunos antes tidos como indisciplinados na categoria mais temida, segregadora e estigmatizante de violentos.

Outro dado merece destaque inicial. Pesquisas vêm mostrando as conexões entre a violência infanto-juvenil e as violências de que crianças, adolescentes e jovens padecem. Entretanto, as indagações e as reações concentram-se mais na condição de réus e agentes infanto-juvenis de atos de violência do que na sua condição de pacientes e vítimas. Este dado traz conseqüências para as pesquisas e reflexóes teóricas, sobretudo na educação. Temos pouca reflexão acumulada sobre como a condição de pacientes, vítimas de tantas formas de violência, afeta os processos de socialização, formação intelectual e ética, identitária e cultural, como afeta os processos de desenvolvimento humano de tantos coletivos de educandos. Temos pouco acúmulo sobre os impactos nos processos de aprendizagem escolar das perversas e destrutivas formas com que a sociedade contemporânea vitima os coletivos de crianças, adolescentes e jovens, sobretudo populares. Deixamonos impactar mais pelo quanto nos incomodam suas condutas na sociedade e nas escolas. Para entender e acompanhar processos de formação desde a infância, o preocupante é que sejam tanto atores quanto vítimas das violências. Que impactos pode ter em suas identidades se saber, desde crianças, segregados como violentos e infratores na sociedade e até nas famílias e nas escolas?

A cultura escolar opera tradicionalmente com parâmetros classificatórios dos educandos. A introdução da categoria alunos violentos introduz um novo parâmetro, que toca em dimensões humanas mais segregadoras, com impactos não apenas nos processos tradicionais de enturmação, avaliação, aprovação-reprovação e gestão dos percursos individuais de ensino-aprendizagem, mas com impactos nos processos de desenvolvimento humano, ético, cultural, identitário de coletivos 
segregados como violentos. Como uma criança-adolescente ou um coletivo de crianças, adolescentes ou jovens elabora o fato de ser catalogado como violentos, infratores, bárbaros em seus processos de conformação de identidades? Como os profissionais desses delicados processos serão capazes de acompanhá-los? São questões trazidas pelas novas formas de segregação que indagam as pesquisas e a reflexão pedagógica.

As classificações de crianças, adolescentes e jovens se radicalizam nas escolas e na sociedade. As categorias de normal-anormal, de aluno sem problemas ou com problemas que a escola aplicava ao rendimento escolar agora têm como referente sobretudo qualidades morais dos alunos, de suas famílias e de sua origem. Quando se classifica por parâmetros de rendimento intelectual se usa a expressão "alunos com problemas de aprendizagem", "repetentes", mas permanecendo na escola, ainda confiáveis. Quando as classificaçôes são por critérios morais se usa a expressão "alunos-problema" porque, quando violentos, logo são estigmatizados, expulsos, segregados do convívio escolar. Desconfiáveis.

Diríamos que as reações à violência infanto-juvenil na sociedade e nas escolas estão provocando uma redefiniçãao e radicalização nos tradicionais parâmetros de classificação, segregação e marginalização de indivíduos e, sobretudo, de coletivos. Os parâmetros morais adquirem novas dimensões políticas na produção da segregação social e cultural. Que papel vêm cumprindo as escolas?

\section{A infância-adolescência no debate público}

A violência infanto-juvenil está posta no debate público. Crianças, adolescentes e jovens "infratores" passaram a ser um dos fatos mais discutidos. Vêm provocando o confronto entre intelectuais, juristas, políticos, jornalistas, ONGs e igrejas. As opiniões, análises e propostas saíram das academias e pesquisas, dos tribunais e tornaram-se expostas. Todos os segmentos da sociedade vêm externando seus pensamentos e juízos, sentimentos e valores. O pensar, sentir, avaliar, julgar e condenar as infâncias infratoras vieram à tona, expostos ao debate aberto, como feridas sociais. A infância sai da esfera familiar e da esfera das escolas para entrar no debate público.

Esse dado parece indicar que a violência, especificamente a violência infanto-juvenil, é um grave problema contemporâneo. E mais, 
que o horror diante das violências e de tantas formas de destruição de seres humanos é um dos sentimentos mais contemporâneos. Que a violência praticada pela infância provoca ainda maior espanto. Daí o debate público que provoca. Conseqüentemente, omitir-se não será contemporâneo. Está posta mais uma indagação para a Pedagogia: entrar nesse debate público será um desafio da contemporaneidade para a educação?

Um ponto para a pesquisa e para o debate, em revistas, congressos, ANPEd, poderá ser se o pensamento educacional entrou e como entrou, se deverá entrar e como nesse debate público, se foi ou não chamado a participar, se se isolou em sua preocupação com a violência nas escolas. Se vem fugindo desse debate como um tema incômodo e escorregadio, se a violência infanto-juvenil incomoda, apenas, porque ameaça a paz nas escolas, se as soluções encontradas são extirpar todo sinal de violência interna, expulsando os alunos tidos como violentos, jogando-os indefesos nas violências das cidades. Se os projetos se limitam a recuperar a paz nas escolas... Se a infância apenas interessa à Pedagogia na qualidade de alunos (Arroyo, 2004a).

Se essa postura for constatada, seria um indicador de que a instituição escolar continua se imaginando distante da sociedade, imune às suas tensões? Durante as décadas recentes a relação educação-escoladocência-sociedade foi um tema recorrente. Tentamos avançar na compreensão dos estreitos vínculos entre sociedade e educação. A dificuldade de os profissionais da educação, de pesquisadores e de publicações entrarem nesse debate público e o fato de não serem chamados a esse debate não seriam um indicador do pouco que se avançou nos vínculos entre educação-sociedade, e entre educação e outros campos do embate social, público sobre as questóes contemporâneas? $\mathrm{O}$ pensamento educacional não é chamado ou entra com timidez nesses debates públicos por não se expor? Por não ter com o que contribuir? Por não por a nu sentimentos, valores, pensares sobre temas tão delicados? Por que se julga distante e descomprometido com o avanço das violências infantojuvenis? Por que o sistema escolar não foi preparado para lidar com essas infâncias? Por que sua função não é educar, mas apenas ensinar?

Talvez este seja um dos campos que o debate público sobre as violências explicita: que, apesar dos avanços no equacionamento da relação educação-sociedade, ainda permanece uma cultura de isolamento 
das instituições escolares, um distanciamento dos problemas e embates mais contemporâneos. Talvez o sistema escolar tenha reduzido sua função a ensinar, a transmitir conteúdos, habilidades, competências para a inserção no mercado. Conseqüentemente tenha estado mais sensível às demandas do mercado do que aos grandes embates da sociedade. Com relação à infância e à juventude, talvez tenha estado mais preocupado em torná-las empregáveis do que em entender os perversos processos de sua destruição por meio das diversas formas de violência. Entrar nesses debates contemporâneos sobre a infância, adolescência, juventude pode significar a percepção de que essas infâncias interrogam a função do sistema escolar e o reducionismo a que foi submetido nas últimas décadas. Secundarizar a entrada nesse debate pode ser uma forma de aumentar o isolamento da sociedade a que foi reduzido o campo da educação.

As escolas e universidades estão sendo pressionadas para se tornarem mais públicas, mais de todos os coletivos diversos. Um caminho para se tornarem mais públicas é serem espaços de embate dos problemas que afetam toda a sociedade. É próprio dos espaços públicos abrirem-se aos debates públicos, coletivos, publicizando conhecimentos e análises, sentimentos, medos e emoções, valores e políticas que afetam os coletivos, sobretudo os mais vulneráveis e marginalizados como, no caso das violências, a infância, a adolescência, a juventude violentadas e temidas. Assumir essas infâncias como indagação pode ser uma forma de tornar as escolas e as universidades mais públicas. Sempre que a infância entra no debate público, o sistema escolar é pressionado para ser mais público.

A fragilidade da escola como espaço público - a fragilidade da proclamação da educação como direito de todos

O reconhecimento da escola como tempo-espaço público e as tentativas de sua configuração como pública têm sido uma das marcas dos embates político-pedagógicos das últimas décadas.

Dois fatos contribuíram nessa configuração: a afirmação da educação como direito de todo cidadão, bandeira dos anos de 1980, e o reconhecimento da infância-adolescência como sujeito de direitos, bandeira dos anos de 1990, com o Estatuto da Infância e da Adolescência 
(ECA). O debate sobre a violência sugere fazer um balanço: a realidade das violências infanto-juvenis e sobretudo reações, sentimentos, medos, contravalores que provoca no embate público e educacional estaria descaracterizando e freando os avanços na configuração da escola como espaço público? Ou estaria mostrando a fragilidade da proclamação da educação como direito de todo cidadão e a fragilidade da proclamação de toda criança e adolescente como sujeito abstrato de direitos abstratos? Questões postas que exigem pesquisa e reflexão teórica. As reações às violências infanto-juvenis na sociedade e nas escolas parecem apontar que, na defesa da educação como direito de todo cidadão, não cabem crianças, adolescentes e jovens considerados infratores, violentos, desordeiros. Conseqüentemente as escolas se atribuem o direito de expulsá-los sumariamente ou recluí-los em espaços e turmas especiais, submetidos a açóes socioeducativas preventivas e recuperadoras. As violências dando o direito à sociedade e às escolas para julgarem quem tem ou não tem direitos.

A contemporaneidade das violências, sobretudo da violência infanto-juvenil, confronta-nos com a conformação da escola como espaço público, com a compreensão dos direitos e especificamente com a educação como direito, com as imagens da infância e especificamente com a afirmação da infância como tempo de direitos. Questôes todas com que vínhamos alimentando as pesquisas, a produção teórica, a formação de educadores-docentes, as políticas educativas, de currículo etc. A violência infanto-juvenil na sociedade e nas escolas talvez esteja explicitando a fragilidade do trato desses campos ou a urgência de sua reconceituação, pesquisa e teorização.

São essas infâncias "violentas" que deixam a descoberto a fragilidade da defesa da educação como direito de todo cidadão, talvez porque tanto a concepção de direito como a de cidadania foram colocadas em um plano tão abstrato que não são capazes de incorporar cidadãos e direitos concretos, infâncias concretas, contextualizadas. Uma questão que nos leva à rica produção teórica do debate atual sobre os direitos universais entendidos como generalistas, descontextualizados, e sua fragilidade na garantia de conformação de políticas e instituições para cidadãos e direitos concretos, contextualizados. Há urgência em dessacralizar conceitos abstratos perante as dificuldades concretas de incluir todas as infâncias no conceito de direito à educação. Os direitos são produtos culturais contextualizados (Herrera Flores, 2005). 
Deparar-nos com cidadãos e infâncias tão chocantes provoca tantos embates porque desconstrói as concepções de cidadania e de direito que cultivamos com tantas certezas político-pedagógicas nas últimas décadas. Mostra a fragilidade dessas certezas. Teremos de pesquisar e teorizar sobre essas crenças e sobre os avanços que inspiraram no campo da educação. Avanços colocados à prova pelas reaçôes da sociedade e dos profissionais da educação diante da violência infanto-juvenil.

A tendência parece ser reconceituar esses conceitos de cidadania e de direitos, torná-los mais restritivos e seletivos: cidadãos entendidos como sujeitos ordeiros, inseridos na ordem cívica, nas normas de participação. Estes teriam direito à educação, à escolarização, ao conhecimento, como direito. Os violentos seriam excluídos desse direito ao convívio, à cidadania, à educação, à escola. Nem sequer seriam objeto de atenção das pesquisas, da produção teórica e das políticas educativas.

Os esforços das últimas décadas por conformar a educação como campo de direitos do cidadão, a partir de concepçôes generalistas, abstratas de cidadania e de direitos, podem resultar na conformação de uma nova e mais perversa exclusão dos cidadãos e dos direitos concretos. O tratamento dado aos cidadãos "violentos", infratores, aponta nessa direção. Todo conceito generalista tende a ignorar as formas concretas, diversas, de vivência da cidadania e ignorar os diferentes contextos de desigualdade social e diversidade cultural (Santos, 2006). Nas instituições educativas está se instalando e legitimando uma forma nova de exclusão: rejeitar, expulsar, não matricular alunos tidos como violentos, por não se conformarem com a concepção de cidadania ordeira, participativa, desde que crítica, tão proclamada em décadas recentes. Essas infâncias não cabem nessas concepções de cidadania e de escola pública.

As concepçôes de cidadania, de direito, de público, construídas nas décadas recentes, passam a operar como parâmetros de classificação e exclusão daquelas infâncias e adolescências que não se enquadram nessas concepções generalistas e abstratas. Com essas concepçôes, lutamos pela escola pública para todos, porém tais concepçōes mostram-se tão frágeis na hora de incluir os ditos violentos. Os avanços havidos na defesa do direito à educação para todos exigem novas pesquisas e reflexão teórica para abrir esses direitos para a diversidade e a desigualdade de formas de viver a infância e a adolescência. A legítima 
proclamação de direitos iguais mostrou não ser suficiente diante do aumento das desiguais formas de viver como indivíduos e, sobretudo, como coletivos.

A fragilidade do reconhecimento da infância-adolescência como sujeitos de direitos

Um processo parecido estaria se dando em relação à segunda bandeira que tanto instigou a conformação da escola como espaço público: o reconhecimento da infância-adolescência como sujeitos de direitos (ECA). Um dos avanços mais significativos foi reconhecer o direito à infância e à adolescência ou o direito a viver esses tempos e ao reconhecimento da especificidade do ser criança-adolescentes, a ser reconhecidos como tais.

O caráter abstrato, generalista da concepção de infância-adolescência e de direito à infância-adolescência está sendo questionado pelas formas diversas de viver a infância-adolescência. Aqueles que contestam essas concepções abstratas da infância e de seus direitos são exatamente crianças-adolescentes concretos, em contextos de viver a infância-adolescência que se afastam da visão generalista. São as "infâncias outras", destruídas como crianças ordeiras e inocentes, tornadas infratoras, culpadas, aquelas que interrogam as concepções generalistas de infância e seus direitos a viver a infância. Essas infâncias outras não se encaixam nesses conceitos. Consequentemente serão excluídas do direito a ser reconhecidas como crianças. Mais uma vez as concepções de infância-adolescência e de seus direitos tornando-se excludentes das infâncias outras. As indisciplinas e violências mostrando o caráter restritivo, segregador das concepçôes de infância e de seus direitos com que trabalhamos. Fomos levados a deixar de ver aqueles que são considerados violentos, indisciplinados, infratores como infância-adolescência, para criar e enquadrá-los em uma categoria ambígua, "menores infratores", sem direito até a serem reconhecidos como crianças e adolescentes. Desprovidos do direito mais elementar: serem reconhecidos como gente, como humanos.

O medo pode levar a essas exclusões, mas também a fragilidade dos conceitos abstratos com que vínhamos conduzindo as políticas e os tratos da infância e seus direitos abre espaço para a exclusão dessas 
infâncias "outras" da categoria abstrata de infância e de direitos. Mostra quão frágeis são esses conceitos quando se defrontam com infâncias tão precarizadas e vulneráveis. Políticas educativas e afirmações de direitos à educação infantil ou fundamental se desmancham no confronto com a infância-adolescência reais, diante de suas condutas transgressoras.

Esses impasses nos levam a rever e a pesquisar as concepções de infância com que o campo da educação ainda opera. Crianças idealizadas, inocentes, anjos, sementes e plantas tenras, massinhas moles moldáveis em mãos carinhosas de jardineiros e oleiros. Tempos de infância, como tempos de ludicidade. Esta visão que já vinha sendo desconstruída, do imaginário pedagógico, volta e reafirma-se pelo avesso, diante dos dados sobre as violências infanto-juvenis. O curioso é que aquela visão que julgávamos superada ainda se revela persistente e volta na hora de avaliar, julgar, condenar e excluir as crianças-adolescentes porque se afastam do parâmetro inocente de infância. Como se a violência infantil fizesse rebrotar tradicionais visões da infância em vez de contribuir para sua superação.

Os estudos sobre a infância vinham mostrando outras visões da infância-adolescência como não mais in-fans, sem fala, sem opinião, sem pensamento, mas uma infância pensante, sujeito de decisões e escolhas, de valores, de liberdade e de autoria própria. Esta visão vinha se afirmando com o reconhecimento da infância-adolescência como sujeitos de direitos e como sujeitos de cultura (Sposito, 1993, Gonçalves, 2006). Os medos, os alertas e as reações às violências infanto-juvenis saem na contramão desses avanços. Colocam em dúvida a capacidade de autoria, de escolhas, de decisão e de liberdade da infância e adolescência. Repõem a tradicional visão de infância sem fala, sem pensamento, préhumana, pré-moral. Criança mais próxima do estado biológico-natural que do estado cultural, humano. Distante da condição de sujeitos de direitos humanos.

As reações tão condenatórias das infâncias catalogadas como infratoras desnudam a tênue consistência em que se fundamenta a relação da sociedade e das instituições educativas com a infância, ao menos com as outras infâncias. Uma visão ainda distante da condição de gente e de cidadãos que esteriliza qualquer pretensão de alicerçar o reconhecimento e o trato dessas infâncias em bases civilizadas, de direitos. Essa visão nos distancia da conformação da escola como espaço 
público e das políticas da infância como públicas. Leva-nos para políticas assistencialistas entregues a agências privadas. A sociedade tem dificuldade de ver as escolas populares como espaços públicos e seus profissionais têm dificuldade de se reconhecer como profissionais do público, porque ainda temos dificuldade de reconhecer a infância e a adolescência populares como sujeitos de direitos. Porque a sociedade ainda os vê como ameaça à ordem e à civilização. $\mathrm{O}$ discurso sobre essas infâncias como sujeitos de direitos é tão frágil que se quebra diante da primeira manifestação de indisciplina e de violência.

Enquanto no imaginário social e pedagógico as representaçóes da infância-adolescência populares forem tão frágeis, o pensamento pedagógico será frágil. As instituiçôes e os profissionais da infância, assim como o pensamento educativo, refletem os imaginários e as formas de viver a infância. Nas últimas décadas nos defrontamos com o repensar das instituiçôes educativas e com o repensar da infância. As reaçôes às violências infanto-juvenis vêm mostrando que ainda está em jogo uma disputa sobre o imaginário da infância e da adolescência, sobretudo populares. Conseqüentemente está em disputa a concepção do público.

\section{Uma disputa por imaginários de infância popular}

Possivelmente a Pedagogia tenha sido uma das áreas que mais vinha se empenhando em recolocar a imagem da infância popular. As campanhas em defesa da escola pública, desde os anos de 1950, para a inclusão da infância e da adolescência populares das periferias urbanas, até a defesa mais recente da escola pública para todos ou a defesa dos recursos públicos para a escola pública, tiveram sempre como horizonte a inclusão das crianças e dos adolescentes populares, por décadas marginalizados das políticas públicas e do público. Todos esses movimentos no campo da educação vinham contribuindo para conformar uma imagem positiva, respeitável da infância-adolescência popular.

As reaçōes diante da violência infantil colocam algumas questóes. Até onde essa imagem mais positiva vinha sendo incorporada na nossa cultura política, elitista e segregadora de tudo o que é popular e especificamente dos filhos do povo? Inclusive, até onde essa imagem menos negativa teria se incorporado no pensamento pedagógico, no imaginário e na cultura escolar e docente? 
Questões que exigem pesquisa e reflexão teórica. As reações às violências infanto-juvenis podem ser indicadoras de que todos esses esforços por conformar imagens menos negativas da infância-adolescência populares ainda não calaram fundo em nossa cultura política nem sequer pedagógica, escolar e docente. É fácil constatar que os embates sobre as violências apontam para sujeitos concretos: crianças, adolescentes e jovens populares. Os catalogados como "menores infratores" são, em sua maioria, populares, pobres, negros. A mídia destaca as violências nas escolas públicas populares. A maioria das pesquisas sobre violência nas escolas tem como amostra escolas públicas. $\mathrm{O}$ assombro e a repulsa à violência vêm recriando e aumentando o medo da infânciaadolescência e juventude populares.

Esses indicadores apontam uma disputa em torno dos imaginários da infância popular (Arroyo, 2004b). Em torno não tanto da miséria, fome, precarização de suas existências e de seus direitos humanos mais básicos, mas uma disputa em torno de sua miséria moral, de sua carência de valores, de dignidade humana. Uma disputa que saia no reconhecimento ou não de sua condição humana. A disputa sobre o imaginário da infância popular nunca se radicalizou tanto porque nunca foi colocada nesses patamares da possibilidade de serem essas pessoas capazes de agir por valores e de serem sujeitos éticos, humanos. A desconfiança sobre a infância popular mostra-se nesses níveis. Essa radicalização do imaginário da infância-adolescência popular toca em cheio no campo da educação e destrói na raiz as tentativas de mais de 50 anos de quebrar imagens negativas da infância popular e de conformar imagens positivas, confiáveis.

Onde situar a fragilidade desses avanços? Seria necessário pesquisar se o fato de colocar a infância-adolescência populares na escola pública teria ou não significado o reconhecimento de sua igualdade cognitiva e moral. Os dados mostram que as crianças populares foram tratadas como menos capazes, com problemas de aprendizagem. A grande maioria dos milhares de alunos reprovados por suposta incapacidade cognitiva foi e continua sendo de crianças e adolescentes populares, pobres e negros. Os persistentes dados de reprovação e catalogação dessas infâncias como menos capazes, como lentos, desacelerados mentais e com problemas de aprendizagem mostram que não superamos a cultura política e pedagógica que os considerava desiguais e menos capazes. Esse imaginário que já existia não foi desconstruído, antes 
foi reforçado com a entrada da infância-adolescência populares na escola pública. Uma escola que não se reconfigurou em sua função pública diante da diversidade e da desigualdade.

Mas o imaginário mais negativo passava por uma visão de inferioridade moral. A segregação mais perversa atingia o plano moral dos valores. As imagens tão enraizadas em nossa cultura política e pedagógica de uma infância indisciplinada, indolente, agressiva e ameaçadora, sem hábitos de trabalho e esforço, sem valores de sucesso porque pobre, negra, mestiça ainda prevalecem no imaginário social, político, escolar e docente.

Durante as últimas décadas assistimos a um confronto em torno desses imaginários na sociedade e no interior das escolas, porém as práticas de enturmaçãa, segregação, classificação e até reprovação, em sua maioria, não ficaram imunes a esses imaginários de inferioridade cognitiva e moral da infância-adolescência popular. Avanços houve, porém lentos. É um campo que exige pesquisas mais cuidadosas e reflexão mais aprofundada.

O espanto diante das violências infanto-juvenis, atribuídas sobretudo aos setores populares e às crianças que freqüentam as escolas populares públicas, chega nesse contexto de tímidos avanços e de tensos embates sobre o imaginário da infância popular. A tendência parece ser não afirmar imagens positivas, mas repor e reafirmar as tradicionais imagens negativas que não tinham sido desconstruídas nem nos espaços das escolas públicas, nem da cultura escolar e docente. No horizonte aparecem mais recuos do que avanços na disputa por imaginários de infância popular, deixando a descoberto a fragilidade dos avanços havidos (Arroyo, 2004b).

Essa disputa está estreitamente atrelada ao embate sobre o imaginário do povo em nossa cultura social, política e pedagógica. A visão da infância-adolescência populares está marcada pela visão que se tem do povo, dos setores populares como um todo. Quando julgamos a infância-adolescência populares reproduzimos os julgamentos sobre o povo, tão persistentes em nossa cultura política. De um lado, a imagem desejada: um povo ordeiro, humilde, pacato, conformado com sua sorte e seu lugar no trabalho e na pirâmide social. Povo pobre, mas conformado. De outro lado: povo malandro, preguiçoso, não dado ao esforço, atrelado aos valores tradicionais, distante dos valores modernos de trabalho, esforço, sucesso, estudo. 
Faz décadas que essas imagens contrapostas, mas complementares, do povo estão em disputa no imaginário social e político, nas diversas interpretações das Ciências Sociais e também no campo da Pedagogia. Disputas que se traduziram ora em projetos de inclusão e integração, ora em projetos de democracia racial. A escola sempre foi equacionada com destaque como a porta para a democracia racial e social, para a inclusão e integração e para a moralização dos setores populares desde a infância.

Nas últimas décadas essa disputa pelo imaginário popular vinha se acirrando com a emergência dos movimentos sociais. Novos atores entrando na arena política: os coletivos populares mais marginalizados e silenciados como tradicionais, pobres, sem valores. Os movimentos populares urbanos da década de 1970, os movimentos do campo desde a década de 1990, assim como os movimentos indígena, quilombola, negro, juvenil, sem universidade, sem teto, dos desempregados... vêm contestando as imagens tradicionais negativas com que foram representados em nossa cultura política. Uma nova imagem passou a entrar na disputa: coletivos populares diversos afirmando-se sujeitos de direitos coletivos, direitos sociais e culturais coletivos. Afirmando-se inclusive sujeitos políticos, de ações políticas, atrevendo-se a formular políticas de reforma agrária, urbana, educativa, inclusive atrevendo-se a exigir políticas afirmativas na universidade, no trabalho.

A disputa aberta com novos contornos em torno do imaginário sobre os setores populares foi-se acirrando nos últimos anos diante dos movimentos sociais populares. A reação veio no sentido de descaracterizar suas propostas de políticas focadas, de confrontá-las com os valores modernos de igualdade republicana ou de respeito ao valor da propriedade da terra, com os valores de sucesso e de mérito para a entrada no sistema escolar público.

A reação repunha a velha visão do povo: se pobres, sem trabalho, sem terra, sem teto, sem escola e sem universidade é porque sem os valores de esforço, trabalho, dedicação, estudo, sem mérito para competir com igualdade na ordem republicana e na democracia moderna. A disputa terminou caindo onde por séculos foi posta: na reafirmação da inferioridade moral dos setores populares e de seus filhos. As tendências repetidas de condenar os diversos movimentos sociais populares como pré-políticos, como violentos e perturbadores da ordem e dos 
padrões de civilidade, assim como as tendências de satanização dos movimentos sociais, repõem a disputa sobre o imaginário do povo no plano de sua inferioridade moral, política e cultural.

Neste contexto de disputa de imaginários sobre os setores populares chega o embate sobre as violências, especificamente a violência de crianças, adolescentes e jovens populares, e mais especificamente nas escolas públicas. Difícil separar processos tão concomitantes, e que vêm provocando disputas tão próximas nas análises e, sobretudo, nos julgamentos sobre os setores populares.

Que indagações mais específicas trazem para o campo da educação essas disputas, análises e julgamentos sobre o imaginário do povo e da infância popular? Que implicações traz para a pesquisa, a reflexão teórica e para a função social das escolas e da docência colocar a disputa no campo dos valores, das condutas e da moralidade popular?

Retomar a função moral das escolas e a autoridade moral dos seus mestres?

É fácil constatar que as violências infanto-juvenis estão trazendo o debate para o campo da moral. O que mais se destaca nas análises é a delinqüência, a falta de valores; o debate gira sobre que tipo de pena aplicar para os menores considerados delinqüentes. Nas escolas, diretores, diretoras e docentes interrogam-se sobre como tratar as condutas, os valores ou a falta de valores e de parâmetros, a falta de limites morais dos educandos. Lamentam-se de que os alunos não reconhecem nem respeitam sua autoridade, não tanto sua autoridade como competentes professores, transmissores de conhecimentos, mas sua autoridade moral para pôr ordem, respeito, disciplina, estudo, trabalho. Como se as indisciplinas, as condutas e as violências estivessem desfocando o imaginário da profissionalidade docente para a autoridade moral. Como se a disputa fosse que as escolas tivessem de redefinir sua função de centros de ensino e transmissão de competências para centros de reabilitação de condutas e de contravalores para valores de ordem e disciplina.

Afirmar a função moral da escola não é novidade, faz parte das análises mais clássicas sobre a escola e a docência. O embate central na Paidéia girava em como formar o sujeito ético, que valores formar e se era possível, e como, ensinar valores (Valle, 2002). 
Durkheim (1952) já definia a autoridade pedagógica em termos de "autoridade moral", como uma delegação da "moral social" na figura do educador para que a moral social fosse representada perante os educandos. Representação do educador como autoridade moral perante os educandos que pressupóe reconhecer a escola como "ambiente moral", como espaço de delegação da "moral social”. Em outros termos a autoridade moral do professor se quebra ou afirma quando a moral social se quebra ou se afirma e quando a escola deixa de assumir ou se assume como ambiente moral. Apesar do conteudismo e cientificismo que invadiram a auto-imagem da escola e da docência, os professores continuaram apelando para a sua autoridade moral e as escolas continuaram tentando se afirmar como ambientes morais. A função moral daria legitimidade às escolas e à docência. A sociedade continua cultivando um imaginário meio sagrado da escola e da docência como tempos e sacerdotes da moralidade social, sobretudo da moralização do povo e dos seus filhos. Sacralidade, moralidade, autoridade pedagógica se reforçaram por décadas na visão social das escolas e de seus mestres.

A antropologia e a sociologia da educação têm destacado essas inter-relaçôes tão persistentes. Bourdieu e Passeron (1983) retomam o conceito de autoridade pedagógica da família e da escola invertendo a relação: não seria o conteúdo moral o que confere a autoridade moral ao educador e à escola, mas é a autoridade moral desta e daquele que confere legitimidade ao que é ensinado e ao ambiente moral da escola e da aula. As escolas e seus mestres mediadores dos processos de legitimação da moral social, da cultura, dos saberes e dos valores legítimos. Por aí se quebra a visão simplista e linear que atribuía a autoridade moral pedagógica das escolas e de seus mestres ao domínio do saber ou à representação da moral social. Entretanto, essa autoridade moral se redefine não apenas quando a relação escolas-mestres com o saber, a cultura e os valores se redefine, mas quando a relação dos educandos com a cultura, os valores, o conhecimento se redefine. Estaríamos nesse momento? As reações às violências apontam nessa direção.

De alguma forma os mestres e as escolas vêem que a ameaça a sua autoridade moral vem das novas relações da infância, adolescência e juventude com os valores, os saberes e a cultura. Com a moral social e escolar. Esta percepção vai se espalhando e acelerando diante das violências infanto-juvenis. Estas representam o questionamento mais assustador à autoridade moral dos professores e à moral social que 
supostamente a escola representa, e que deveria reproduzir como ambiente moral.

As reações já estão postas no embate: Qual a função da escola e da docência? Ensinar, transmitir competências para a inserção no mercado? Garantir o direito ao conhecimento, às ciências e tecnologias? Que espaços há para a educação e formação ética, para o trato dos valores? Não parece fácil reassumir essa tradicional função da escola como aprendizado de valores, como ambiente moral. Há resistências contra as imagens cristalizadas da instituição escolar como instituição ensinante, transmissiva, bancária. Entretanto, o problema das condutas, sobretudo indisciplinadas e violentas, pressiona sobre essas imagens cristalizadas. As reações apontam para reafirmar a autoridade moral e disciplinar das escolas públicas e, sobretudo, de seus mestres. Observam-se tendências a regimentos escolares mais rígidos, disciplinas e penalidades e até expulsões sumárias dos indisciplinados. Até negar o direito à matrícula dos ditos violentos. A tendência é recuperar formas de administração mais centralizadas perante a bandeira da gestão democrática das escolas, defendida desde os anos de 1980. Observa-se a recuperação de didáticas mais autoritárias nas salas de aula, ante as metodologias mais dinâmicas, dialógicas e participativas. Observa-se, sobretudo, o discurso moralizante da infância-adolescência popular ante a ausência educadora e moralizadora das famílias e da sociedade.

Moralizar os pobres, o povo, os indolentes sempre foi uma missão delegada pelas elites ao sistema escolar público. Função moralizadora que a escola não estaria cumprindo, como revelam as violências infanto-juvenis. Diante de tantas indisciplinas os discursos propõem que retomem as escolas essa sua função precípua: moralizar os bárbaros. Este foi o discurso mais repetido perante o espanto diante dos menores infratores. Uma disputa sobre o imaginário do povo e da infância popular que leva a uma acirrada disputa sobre a função das escolas públicas e dos seus profissionais.

Questões bastante diferentes daquelas que ocuparam as pesquisas e a reflexão teórica em décadas recentes de progressismo democrático. Questões que interrogam as políticas educativas, de currículo e de formação de pedagogos, docentes e administradores das escolas. Dependendo do equacionamento dado às condutas tidas como violentas e indisciplinadas da infância-adolescência, tenderemos a equacionar a 
função social, cultural e moral das escolas e da docência. Talvez nunca antes a Pedagogia foi tão interrogada pelos valores, pelas condutas e pela moralidade dos educandos.

\section{Essas infâncias, um estranho incômodo?}

Lembrávamos que o debate público sobre as violências infantojuvenis destaca menos sua vulnerabilidade social do que sua vulnerabilidade moral. Os debates têm girado em torno de sua carência de valores, de sua recuperabilidade ou irrecuperabilidade moral. Predomina a visão de que essas infâncias infratoras são irrecuperáveis, conseqüentemente a educação pouco teria a fazer.

Essa visão é um desafio frontal para a Pedagogia. Essas infâncias trazem para o debate pedagógico as possibilidades e os limites de humanização com que se defrontam. Esses processos são irreversíveis? Chegaram a níveis de desumanização que tornam essas infâncias moralmente irrecuperáveis? Ainda terão efeito medidas educativas, ou não há mais espaço para a educação? Questôes que nos levam ao cerne da teoria pedagógica, das didáticas e da função social da escola e da docência.

A caracterização tão negativa dessas crianças no discurso escolar e extra-escolar aponta para uma descrença em sua educabilidade. Os termos em que são enquadradas - menores, delinqüentes, infratores as exclui das referências de humanidade que o termo crianças carrega. Os menores aparecem como restos de demolição de seres humanos. Logo à margem de todo processo de educação. Apenas restos para reclusão ou eliminaçãa? As altas porcentagens de jovens e adolescentes populares mortos ou exterminados revelam a descrença da sociedade em sua educabilidade.

Essa descrença na educabilidade dessas infâncias contrasta e interroga a recuperação que a Pedagogia vinha fazendo sobre educar como humanizar, formar, desenvolver os educandos como seres humanos. Vínhamos trazendo de volta a educação para seu lugar de onde foi expatriada: para a Pedagogia, a escola, as aprendizagens humanas, a formação da mente, dos valores, das identidades, para a formação dos sujeitos éticos, culturais... À medida que avançávamos nessa recuperação da educação, a desconfiança de que essas infâncias sejam educáveis passa a ser posta com destaque no embate público. 
A dúvida mais destrutiva para a Pedagogia é não acreditar na educabilidade do ser humano, da infância que por ofício acompanha. Neste sentido, as violências infanto-juvenis e os embates que elas provocam trazem hoje as indagaçóes mais desestabilizadoras para o pensar e o fazer pedagógicos.

Esses julgamentos tão duros dessas infâncias podem nos alertar sobre uma realidade que, desde as pesquisas e reflexões do campo escolar, não aparece com todos os seus perversos contornos: de fato, as formas de viver a infância-adolescência vêm se precarizando até extremos desumanizadores e até formas de socialização embrutecedoras. Para milhôes de crianças, adolescentes e jovens se torna penoso e tortuoso fazer percursos de humanização em contextos tão desumanos. Tem fundamento a descrença de que essas infâncias ainda sejam humanizáveis nesse contexto.

O grave é que essas análises vão se infiltrando no discurso pedagógico. Desconfia-se da educabilidade dessas infâncias, a tal ponto de serem expulsas das escolas ou reclusas em agrupamentos especiais. Vem se afirmando uma cultura de que a escola pública deve estar aberta apenas para os humanizáveis. Quando as possibilidades de humanização e de educabilidade são vistas como uma exceção, inclusive desde a infância, a Pedagogia se autodestrói. Será possível reverter essa visão tão pessimista e essa redução do fazer educativo como uma tarefa de exceção? Para poucos?

As violências infanto-juvenis e, sobretudo, os embates que vêm provocando podem destruir as crenças que justificaram por séculos a Pedagogia: acreditar nas possibilidades de todo ser humano, desde a infância, se tornar humano, acreditar que toda criança-adolescente é perfectível. Quando essa crença inerente ou constituinte da Pedagogia se perde, o pensar e fazer pedagógicos perdem seu sentido histórico, social e cultural.

Resistindo a perder essas crenças, um ponto parece exigir novas pesquisas e reflexão: a educabilidade, o desenvolvimento humano supõem horizontes de vida e de humanização, supõem contextos humanizadores. As infâncias tão precarizadas desafiam visões lineares, progressivas, triunfalistas de formação e desenvolvimento humano, de educabilidade. Paulo Freire (1987) tinha-nos advertido que os processos de humanização vêm historicamente acompanhados de 
brutais e opressivos processos de desumanização. Processos pedagógicos pelo avesso.

Sobre esses processos sabemos pouco. Poucas pesquisas e pouco saber acumulamos sobre a desumanização a que tantas infâncias estão submetidas. As violências infanto-juvenis revelam apenas a desumanização infantil que mais incomoda aos pacíficos. Tanto a sociedade quanto a Pedagogia pouco sabem sobre a pluralidade desses processos. Muitos silenciados, propositalmente. Estranhos à reflexão pedagógica, tão estranhos quanto as crianças que mostram sua face desfigurada. A estranheza que essas infâncias provocam na Pedagogia e na sociedade está em que nos obrigam a manter-nos atentos, em diálogo de pesquisa, reflexão e ação com zonas de educabilidade e desumanização que não nos são familiares.

A estranheza maior talvez venha de que os tortuosos percursos dessas infâncias dessacralizam concepções de infância, de educação e de desenvolvimento humano, de escola, de currículo e de docência. Todo processo de dessacralização nos choca como uma profanação. Essas infâncias ousam profanar, dessacralizar nossas crenças. Incomodam e indagam a Pedagogia.

Recebido em julho de 2007 e aprovado em agosto de 2007.

\section{Referências bibliográficas}

ABRAMOVAY, M. et al. Juventude, violência e vulnerabilidade social na América Latina. Brasília, DF: UNESCO; Cortez, 2002.

ARROYO, M.G. Imagens quebradas: trajetórias e tempos de alunos e mestres. Petrópolis: Vozes, 2004a.

ARROYO, M.G. Violência nas escolas: uma disputa entre imaginários de infância e de docência. In: CONGRESSO IBERO-AMERICANO SOBRE VIOLÊNCIAS NAS ESCOLAS, 1., 2004, Brasília. Anais... Brasília, DF: UNESCO, $2004 \mathrm{~b}$.

BOURDIEU, P.; PASSERON, J.C. A reprodução. Lisboa: Vega, 1983. DURKHEIM, E. Educação e sociologia. São Paulo: Melhoramentos, 1952. 
FREIRE, P. Pedagogia da esperança. São Paulo: Paz \& Terra, 1987.

HERRERA FLORES, J. Los derechos humanos como produtos culturales: crítica del humanismo abstrato. Madri: Catarata, 2005.

GONÇALVES, L.A. Narrativas da violência no meio escolar: limites e fronteiras, agressão e incivilidade. Pro-Posiçôes, Campinas, v. 13, p. 85-98, dez. 2002.

GONÇALVES, L.A. Juventude, lazer e vulnerabilidade social. In: SoaRes, L.; Giovanetti, M.A.G.C.; Gomes, N. (Org.). Diálogos na educação de jovens e adultos. Belo Horizonte: Autêntica, 2006.

SANTOS, B.S. A gramática do tempo: para uma nova cultura política. São Paulo: Cortez, 2006.

SPOSITO, M. A sociabilidade juvenil e a rua: novos conflitos e ação coletiva na cidade. Tempo Social, São Paulo, v. 5, n. 1-2, p. 161-178, 1993.

VALLE, L. Os enigmas da educação. Belo Horizonte: Autêntica, 2002. 